\title{
A Longitudinal Analysis of Adolescent Substance Use and School Motivation Among African American Youth
}

\author{
Marc A. Zimmerman and Karen H. Schmeelk-Cone \\ University of Michigan, Ann Arbor
}

\begin{abstract}
Cross-sectional research has shown a link between adolescent substance use and educational motivation. The purpose of the current study was to examine this link in a longitudinal sample of African American youth. The study examined the interrelationships between alcohol and both marijuana use and school motivation over the high school years and their effect on graduation in 681 African American adolescents (50.8\% female). School motivation was shown to relate to subsequent alcohol use throughout high school and marijuana use early in high school. School motivation did not affect graduation status, but alcohol and marijuana use were related to a lower likelihood of graduating from high school. Some gender differences and differences among those who had tried alcohol or marijuana at the first wave as opposed to those who had not tried each substance were found. The findings support a systems model where school experiences can affect substance use, which, in turn, can affect the completion of high school.
\end{abstract}

For the last several decades, concern about keeping children in school and off drugs has been a major public policy goal. Many interventions have been implemented focusing on either school dropout or drug use, whereas research has frequently indicated that variables related to school attitudes, performance, and attendance are associated with use of cigarettes, alcohol, and other drugs, especially during the high school years. School-related variables such as grades, school motivation, and leaving school before

Requests for reprints should be sent to Marc A. Zimmerman, Department of Health Behavior and Health Education, University of Michigan School of Public Health, 1420 Washington Heights, Ann Arbor, MI 48109-2029. 
graduation have been identified consistently as risk factors for adolescent drug and alcohol use (Bachman, O'Malley, \& Johnston, 1980; Barnes \& Welte, 1986; Coombs, Wellisch, \& Fawzy, 1985; Dewey, 1999; Johnston \& O'Malley, 1986; Kandel, 1980; Maton \& Zimmerman, 1992). Investigators who have examined adolescent drug use before and after school dropout also found that alcohol and other drug (AOD) use both lead to and are a consequence of negative school outcomes (e.g., dropout, low grades; Friedman, Glickman, \& Utada, 1985; Mensch \& Kandel, 1988; Newcomb \& Bentler, 1986).

This article describes a longitudinal analysis of school motivation and alcohol and marijuana use in a sample of African American youth. This study built on the research literature in several crucial ways: (a) withingroup analysis (African Americans) avoids inappropriate comparisons and provides useful insights for a specific ethnic group, (b) analyses of African American adolescents adds to the emerging research on specific ethnic groups, and (c) the lead-lag relationship throughout the high school years and into the post-high school years has been underexamined.

\section{Theoretical Perspectives}

When describing the interactions between educational motivation and substance use, several models can be hypothesized. First, if we suspect that the relationship is reciprocal, where educational motivation and substance use affect each other over time, this suggests a problem behavior model as reported by Bryant, Schulenberg, Bachman, O'Malley, and Johnston (2000) or a social control model of general deviance as reported by Hirschi (1998). Both models posit that problems such as truancy, lack of school bonding, and AOD use are all related to an underlying behavioral disposition of deviance. Thus, no directionality can be discerned. Associations between substance use and academic motivation have been found in both longitudinal and cross-sectional studies, including associations of substance use with grades; boredom; feelings that schoolwork is important; lower educational aspirations (Paulson, Coombs, \& Richardson, 1990); and less commitment to education and involvement in schoolwork, sports, and outdoor activities (Thorlindsson \& Vilhjalmsson, 1991). Lower grades were related to substance use in males, but not in females in a cross-sectional study of 10th graders (Luthar \& D'Avanzo, 1999). In a review of 43 studies on substance use and academic factors, Dewey (1999) found that grade point average (GPA), absenteeism, educational plans, and high school noncompletion were consistently associated with substance use. Dewey suggests that the relationship between school variables and AOD use may be a reciprocal 
relationship. Although the literature shows strong evidence of an association between academic success or motivation and less AOD use, a possible reciprocal relationship shown over time has not been fully tested.

A second model suggests that use of alcohol and marijuana would decrease school interest and engagement. In this motivational deficit model, substance use would always precede school apathy. Lack of school motivation, involvement, and competence has been related longitudinally to earlier (Brook \& Newcomb, 1995) and increasing drug use (Wills, McNamara, Vaccaro, \& Hirky, 1996). Sanders, Field, and Diego (2001) found a small but significant effect of alcohol use on academic expectations, with larger effects of cocaine and marijuana use on academic achievement. Much of the work examining the effect of drug use on school variables has focused on dropping out of high school. Newcomb and Bentler (1986) found that having low educational plans and using hard drugs predicted dropping out of high school. In another study, 7th-grade cigarette use, but not alcohol or marijuana use, was related to dropout by 12th grade (Ellickson, Bui, Bell, \& McGuigan, 1998). Friedman et al. (1985) found that $51 \%$ of regular drug users in 9th, 10th, or 11th grade did not graduate high school. They also reported that a drug severity index, increased use over time, and degree of increase in overall drug use predicted dropout. These findings suggest that substance use could lead to low school motivation, increasing the chances of dropping out of school.

Finally, a school disengagement model can be posited where students are not engaged by the school. Thus, the students would seek stimulation and challenge elsewhere, leading to AOD use. This model is similar to Hawkins and Weis's (1985) proposed social development model, where educational motivation is decreased by school failure, which leads to association with delinquent peers and substance use. In a retrospective study of college students, those with higher commitment to school were less likely to have used alcohol and marijuana, and involvement in school activities was related to less marijuana use (Free, 1994). Those identified as potential dropouts in high school are more likely to use all categories of drugs, and they show lower levels of control and more adverse consequences from drug and alcohol use than those at low risk for dropout about a year later (Eggert \& Herting, 1993). GPA and academic problems may be seen as proxies for school motivation as in Ellickson, Tucker, Klein, and McGuigan's (2001) study, which found that academic problems in 8th grade were related to more high-risk drinking in high school seniors. Schulenberg, Bachman, O'Malley, and Johnston (1994), however, did not find direct effects between senior year GPA or college plans and drug use 3 to 4 years later. They did find that those who had high GPAs and did not use drugs in high school were less likely to have 
initiated use in the years following graduation. In addition, being academically motivated (e.g., having college plans) was associated with less cigarette use and more alcohol use but had no effect on illicit drug use in young adulthood. Schulenberg et al. suggested these effects are typically mediated through high school drug use and post-high school experiences. In a recent longitudinal study, Bryant et al. (2000) found that 8th-grade school misbehavior and low academic achievement were related to 12th-grade cigarette use, but school bonding, though concurrently related to less cigarette use, did not predict later cigarette use levels. Thus, some evidence supports a school disengagement model where early low school motivation is related to later AOD use.

Most of these studies, however, examined either majority White samples or combined ethnic groups for analyses. Wills et al. (1996) is one exception. They did not find racial differences between fairly equal numbers of White, Hispanic, and African American youth by substance use categories. However, Ellickson et al. (1998), in their examination of the effects of substance use on dropout, found that alcohol use was more of a risk for dropout among African American as compared with White adolescents. A limitation to this examination is that only $8 \%$ of their sample was African American; therefore, a comparison of these two ethnic groups in their study may not provide definitive conclusions. Additionally, by simply comparing two or more ethnic groups, researchers tend to attribute risk for school failure or dropout, for example, to race membership alone (Watson, 1990) instead of examining within-group effects. It may be more appropriate to examine these issues within ethnic groups instead of across them for several reasons. First, school experiences may differ across groups, systematically raising questions about spurious variables that may explain findings. It is reasonable to assume that African American youth in schools with predominantly White youth may have different experiences than African American youth in predominantly African American schools, and vice versa. Second, school characteristics may differ across ethnic groups, as minority youth are more often found in poorer, more urban school districts than are White youth (Adams \& Singh, 1998; Luthar \& D'Avanzo, 1999; Wallace et al., 1999). It is also likely that these schools would be more wanting of educational resources such as teachers for smaller classes (Murdock, 1999), and the school facilities may be more tattered and the context of the school may be more interpersonally threatening. Third, ethnic differences such as family context and process, cultural traditions and identity, and experiences such as racism and discrimination suggest that comparisons across ethnic groups that do not take such issues into account may not adequately assess group differences. Fourth, ethnic differences in school dropout and drug use (Ellickson et al., 
1998) suggest that comparisons across groups is evidence that the mechanism differs and needs to be considered within groups (Wallace et al., 1999). Most studies of school outcomes and substance use that employ ethnic group comparisons do not consider these issues. A withinethnic group approach helps avoid potential spuriousness introduced by the multiple differences found across ethnicity. Future research could better examine between-group differences based on specific relationships found in within-group studies.

\section{Differences in Relationships of Educational Motivation and Performance to Alcohol and Marijuana}

Different substances often show differences in presence and strength of relationships with school motivation and performance in many samples. Mensch and Kandel (1988) found differing effects for alcohol and marijuana use on dropout in males and females. Marijuana use was more strongly related to dropout in men than in women. For both genders, alcohol use showed a weak effect on dropout, as it did not further differentiate between those who dropped out and those who stayed in school once both cigarette and marijuana use were taken into account. More recently, Dornbusch, Erickson, Laird, and Wong (2001) reported that marijuana use was related weakly to school connectedness, but only in high socioeconomic status (SES) communities. Alcohol use was not related to school connectedness in any context. When examining the relationship of substance use to school variables, college plans, GPA, and truancy over many cohorts, Brown, Schulenberg, Bachman, O'Malley, and Johnston (2001) found that marijuana use was consistently related to educational motivation and performance, whereas alcohol use was related only to GPA and truancy. Marijuana use was a stronger predictor than alcohol use. These studies suggest that marijuana use is more closely related to educational motivation than is alcohol use. In a study comparing ethnic groups, however, this hypothesis was not supported (Ellickson et al., 1998). Although in the total sample marijuana use was more predictive of dropping out than was alcohol use, alcohol use was more predictive of dropout among African Americans than among Whites. Marijuana use, however, was not predictive of dropout among African Americans.

\section{Sex Differences, AOD Use, Educational Motivation, and Performance}

Few researchers have examined sex differences in the relationship between AOD use and school attitudes (Dornbusch et al., 2001; Ellickson 
et al., 1998; Luthar \& D'Avanzo, 1999; Mensch \& Kandel, 1988; Stronski, Ireland, Michaud, Narring, \& Resnick, 2000). Although Dornbusch et al. (2001) found no gender or race differences in the relation of school connectedness to substance use, several other researchers have found gender differences. Ellickson et al. (1998) found that females were more likely than males to drop out when both had similar educational aspirations, academic performance, and drug use levels, but their sample was predominantly White. Other studies have found relationships for substance use with lower grades (Luthar \& D'Avanzo, 1999) or dropout, low academic achievement, and having low career optimism (Stronski et al., 2000), but only for males. Mensch and Kandel (1988) found that for men, early initiation of alcohol, marijuana, or other drug use was related to dropping out, whereas for women, only early initiation of cigarette and marijuana use was associated with dropping out. The inconsistency of these studies suggests continued examination of sex effects when examining the relationship of AOD use and educational motivation.

\section{Timing of Substance Use Initiation}

Finally, early initiation of substance use can be detrimental. Early initiators are more likely to drop out of school (Bray, Zarkin, Ringwalt, \& Qi, 2000) and have higher levels of alcohol misuse and high-risk drinking by 12th grade (Ellickson et al., 2001). Ellickson et al. (2001) found much higher risk for later alcohol misuse and high-risk drinking if the respondents had initiated use by 7th grade than if they had not initiated until 10th grade. Alcohol use and possibly some experimentation with marijuana could be considered normative in the high school years, whereas use before high school is indicative of other behavior problems (Newcomb \& Bentler, 1986; Wills et al., 1996). Thus, a comparison between respondents who have initiated use of these substances before, as opposed to after, the start of high school as in Bryant et al. (2000) may differentiate effects within our model and elucidate treatment strategies for before and after the high school transition.

\section{Overview of the Present Study}

Most of the studies on AOD use, school attitudes, and graduation are cross-sectional or include only two time points. Consequently, it is difficult to determine timing of effects or discover whether a reciprocal relationship exists. Additionally, the longitudinal studies cited typically have only one time point of data collection while the respondents are in high school 
and may not be able to detect longer term effects. Most studies also include predominately White samples, and no research has examined African Americans alone. The few studies that examined race effects have found some racial differences, but comparisons may not be appropriate because of different contexts and experiences across racial groups. Luthar and D'Avanzo (1999), for example, did a comparison of suburban and innercity youth where they did not find racial differences. Their suburban sample, however, was $82 \%$ White and only $1 \%$ African American, whereas the inner-city sample was only $13 \%$ White and $41 \%$ African American. It is likely that racial differences may be obscured by using geographic area in the analysis and by classifying all minorities as one group. Thus, studies that examine only one ethnic group may help us more fully understand the connections between AOD use and school motivation within that group.

The present study examined school motivation and alcohol and marijuana use over time, with an outcome of graduation status. The theoretical models presented in the preceding review suggest using motivation and achievement separately, because the constructs are distinct. Also, we wished to examine the effects of motivation independent of achievement on AOD use and graduation status. The present study examined the effect of academic attitudes and AOD use on graduation status in a sample of African American youth throughout their high school years. We wished to examine whether: (a) drug use and school motivation affect each other over time equally or if predictive power is unequal, (b) those with more drug use and less motivation will be less likely to have received a high school diploma by 18 months after the expected graduation date, and (c) alcohol use is more strongly related to school motivation and graduation status over time than marijuana use. In a subanalysis, we also examined gender differences and differences between those who have used alcohol or marijuana by the first wave with those who have not.

\section{METHOD}

\section{Sample}

Participants were 681 African American adolescents (50.8\% female) who participated in the first five waves of a longitudinal study of school dropout and drug use in a large Midwestern city. They were sampled from the four public high schools in the city. About half (49\%) of the total ninthgrade population of the four schools sampled was selected if they met the following criteria: (a) had a GPA of 3.0 or below in eighth grade, (b) had no emotional impairment or developmental disability, and (c) were White, 
African American, or mixed White and African American. Of the 936 students who were invited to participate, a total sample of 850 respondents (93\% of those invited), of which 681 were African American, was assessed in Wave 1. Retention rates over the next four waves from the Wave 1 sample were $94 \%, 91 \%, 89 \%$, and $69 \%$. Sample loss over time in this study was mainly due to refusal to continue participation and moves out of the area that were not successfully tracked. The large sample loss at Wave 5 was due to the 2-year time gap between Waves 4 and 5 that occurred after most participants had left high school. Because of the high mobility of the sample, even before Wave 5, respondents were difficult to find outside the school setting within the time frame of data collection.

Attrition analyses using the main study variables showed only a slightly higher rate of Wave 1 past-year alcohol use for those who did not participate in Wave $3, t(52.557)=2.683, p<.01$. No other variables showed differences between those who participated and those who did not participate in Waves 2 through 5. Their mean age at Wave 1 was 14.6 $(S D=.66)$. SES was assessed by prestige scores of parents' occupation (Nakao \& Treas, 1990a, 1990b). If measures for both parents were reported, the higher of the two was used. The mean prestige score was 39.95 $(S D=10.40)$ indicating a blue-collar occupation (e.g., manufacturing). The 125 White and 26 biracial youth were excluded from this study because they constituted too small a sample for separate or group analysis.

\section{Procedure}

Data were collected in five waves. At Wave 1 (1994), all participants were in the ninth grade. Participants were reinterviewed for the next 3 years at 1-year intervals whether they were in or out of school. Wave 5 (1999-2000) data were collected approximately 2 years after Wave 4 .

Structured, face-to-face interviews were conducted with students in school or in a community setting if the participants could not be found in school. Wave 5 interviews were primarily conducted in a community setting. The interviews lasted 50 to $60 \mathrm{~min}$. When the interview portion was done, participants completed a self-administered, paper-and-pencil questionnaire about alcohol and substance use, sexual behavior, and other sensitive information. Respondents were informed that all information was confidential and subpoena protected.

African American interviewers conducted between $46 \%$ and $66 \%$ of interviews, and females conducted between $62 \%$ and $100 \%$ of interviews over the first 4 years. Analyses on a broad range of variables from the larger study showed no effects by interviewer race or gender (Ramirez- 
Valles, Zimmerman, \& Newcomb, 1998). Interviewers were trained community members and college students, most of whom were native to the area.

\section{Measures}

Alcohol use. The latent construct for alcohol use consisted of three items. The first two were reported alcohol use over the last year and over the past 30 days. These items used a 7-point scale from 1 (none) to 7 (40+ times). The third item was binge drinking ( 5 or more drinks in a row) within the last 2 weeks using a 6-point scale from 1 (none) to $6(10+$ times). These are the same items used in the Monitoring the Future study (Johnston, O'Malley, \& Bachman, 1988). Means and standard deviations for these variables over the four waves are shown in Table 1.

Marijuana use. The latent construct for marijuana use consisted of reported marijuana use over the last year and over the past 30 days (both using the same 7-point scale as alcohol). Means and standard deviations for these variables over the four waves are shown in Table 1.

School motivation. The latent construct for school motivation was measured by two scales: school bonding and school usefulness. The school usefulness scale is the sum of two 5-point Likert items: "Last year, how often did you feel that your schoolwork was useful?" and, "How important do you think the things you learned in school last year are going to be in your later life?"' This scale was reverse-coded such that higher scores on this scale relate to the respondent's feeling that schoolwork and learning are useful or important. The two-item

TABLE 1

Means and Standard Deviations for Main Study Variables Over Time for the Total Sample

\begin{tabular}{llcccc}
\hline Latent Variable & \multicolumn{1}{c}{ Indicators } & Wave 1 & Wave 2 & Wave 3 & Wave 4 \\
\hline \multirow{2}{*}{ Alcohol use } & Alcohol use (year) & $1.98(1.50)$ & $2.15(1.58)$ & $2.21(1.72)$ & $2.36(1.70)$ \\
& Alcohol use (month) & $1.58(1.08)$ & $1.68(1.10)$ & $1.74(1.28)$ & $1.69(1.24)$ \\
& Binge drinking & $1.26(0.81)$ & $1.29(0.80)$ & $1.30(0.87)$ & $1.37(0.96)$ \\
Marijuana use & Marijuana use (year) & $1.96(1.70)$ & $2.49(2.06)$ & $2.51(2.15)$ & $2.55(2.16)$ \\
& Marijuana use (month) & $1.69(1.43)$ & $2.00(1.69)$ & $2.02(1.75)$ & $1.97(1.75)$ \\
School motivation & School usefulness ${ }^{\mathrm{a}}$ & $7.67(1.75)$ & $7.27(1.89)$ & $7.25(1.99)$ & $7.28(2.01)$ \\
& School bonding $^{*}$ & $2.82(0.66)$ & $2.85(0.63)$ & $2.94(0.62)$ & $2.94(0.64)$ \\
\hline
\end{tabular}

anange for this variable is 2 to 10 . 
correlations over all 4 years ranged from .20 to .37 . School bonding was measured by means of seven items from Battin-Pearson et al. (2000). Items included: "I like school" and "I do extra work on my own in class." The items used a 4-point Likert scale from 1 (strongly disagree) to 4 (strongly agree). Cronbach's alphas over all 4 years ranged from .72 to .80 . Means and standard deviations for these variables over the four waves are shown in Table 1.

All respondents were in school in Wave 1, 2.6\% reported dropping out of school in Wave 2, 4.3\% in Wave 3, and $11.2 \%$ in Wave 4 . We assessed overall dropout by examining whether the respondents had graduated high school 2 years after the Wave 4 assessment. At this time, 112 (16.4\%) had not received an high school diploma or a general equivalency diploma (GED). Also, only 2 respondents had missing data for three waves, and 17 were missing data from two waves. Data were collected on school dropouts. If they were very recently in school (or if they dropped out after our data collection), they filled out the school-related questions. For the structural equation model (SEM) analyses, missing scores were filled in using the full information maximum likelihood (FIML) estimates. For other analyses, respondents with missing data were dropped.

Graduation status. Graduation status was measured at Wave 5 from the self-report of highest level of education achieved. A two-group variable was defined as either not having received a high school diploma or GED, or having received a high school diploma or GED. We attempted to ascertain the graduation status of respondents who did not participate in Wave 5 by obtaining school records of graduation status. These records were not used for several reasons. First, for respondents who participated in Wave 5, the school records and self-reports did not always agree. Second, because of movement outside of the original four schools surveyed, school data were not complete for all respondents. Finally, the schools only kept records past the expected graduation date for those who remained in school; therefore, the timing of the assessment was not the same as our Wave 5 assessment and the schools did not keep records on those receiving a GED as opposed to a high school diploma.

\section{Data Analytic Strategy}

Our data analytic strategy included four steps. First, latent constructs for Waves 1 through 4 for alcohol use, marijuana use, and school motivation were created. The measurement models for these constructs were tested using a confirmatory factor analysis separately for each latent construct 
(using AMOS 4.0). ${ }^{1}$ For all models, prior wave factors predicted subsequent year factors. Next, time-lag, saturated-path models were tested. The first path model examined alcohol use at the first four waves, predicting and being predicted by school motivation at the first four waves, with graduation status (Wave 5) predicted by alcohol use and school motivation in Wave 4. We repeated this analysis for marijuana use. Finally, we examined differences in the models by respondent gender or by whether the respondent had begun using alcohol or marijuana by the first wave.

\section{Power Analyses}

SEM power calculations described by MacCallum, Browne, and Sugawara (1996) suggest ample statistical power. Our most complex SEMs have up to $164 d f$, but if we assume only $30 d f$ and estimate power based on the probability of rejecting the hypothesis of not a close fit with the data when true model fit is excellent (the most stringent test; see MacCallum et al., 1996), our power with a sample size of 450 is more than .85. MacCallum et al. showed that power of .80 is achievable with alpha $=.05$ and $30 \mathrm{df}$ with a sample of 366 for not a close model fit (for $d f=100$ the minimum sample size is 178). Thus, we should have ample power for our SEM analyses with 681 respondents.

\section{RESULTS}

\section{Measurement Models}

Three measurement models were performed in AMOS where all waves of each latent variable were predicted by the previous wave. Several corrections were made by correlating error variances of the same variables over time to create better fitting models. For alcohol use, the beta weights for the latent variables predicting the following wave ranged from .56 to .61 (all $p s<.05$ ), and the fit statistics were: $\chi^{2}(42)=211.62 ; \chi^{2} / d f=5.04$; $\mathrm{CFI}=.986$; RMSEA $=.077$. For marijuana use, the beta weights for the latent variables predicting the following wave ranged from .68 to .78 (all

\footnotetext{
${ }^{1}$ We were able to use the complete data set because AMOS automatically computes FIML estimates for missing data. This method is more likely to produce less biased results than listwise deletion, pairwise deletion, and means imputation (at least when the missing data are missing at random). We found this method to be acceptable because most of our missing data were due to attrition, where most respondents who have missing data are missing one complete wave of data, not specific sets of variables. For more information, see Wothke (2000).
} 
TABLE 2

Factor Loadings for Latent Factors in Measurement Models

\begin{tabular}{llcccc}
\hline Latent Variable & \multicolumn{1}{c}{ Indicators } & Wave 1 & Wave 2 & Wave 3 & Wave 4 \\
\hline Alcohol use & Alcohol use (year) & .74 & .77 & .87 & .83 \\
& Alcohol use (month) & .88 & .90 & .86 & .90 \\
\multirow{4}{*}{ Marijuana use } & Binge drinking & .52 & .72 & .66 & .73 \\
& Marijuana use (year) & .95 & .93 & .87 & .90 \\
School motivation & Marijuana use (month) & .88 & .86 & .87 & .96 \\
& School usefulness & .51 & .34 & .55 & .50 \\
& School bonding & .73 & .80 & .79 & .81 \\
\hline
\end{tabular}

Note. All loadings are significant $(p<.05)$.

$p s<.05)$, and the fit statistics were: $\chi^{2}(10)=38.44 ; \chi^{2} / d f=3.84 ; \mathrm{CFI}=0.997$; RMSEA $=.065$. For school motivation, the beta weights for the latent variables predicting the following wave ranged from .78 to .83 (all $p s<.05)$, and the fit statistics were: $\chi^{2}(11)=19.87 ; \chi^{2} / d f=1.81$; CFI $=.999$; RMSEA $=.034$. Factor loadings for each item at each wave are in Table 2.

\section{Alcohol Use and School Motivation}

A time-lag model using the latent variables of alcohol use and school motivation at Waves 1 through 4 with the two Wave 1 variables correlated was examined. This model also included both Wave 4 alcohol use and school motivation predicting graduation status. The final model indicated a correlation between alcohol use and school motivation at Wave 1; small but significant effects of school motivation at Waves 1,2 , and 3 on alcohol use at Waves 2,3 , and 4 ( $\beta \mathrm{s}=-.15,-.17$, and -.09 , respectively); and an effect of alcohol use at Wave 4 on graduation status $(\beta=-.20)$. The fit statistics comparing the saturated model and the final model with nonsignificant paths removed are reported in Table 3 . The final model fit statistics were: $\chi^{2}(164)=477.499 ; \chi^{2} / d f=2.91 ; \mathrm{CFI}=.989$; RMSEA $=.053$. Although this $\chi^{2}$ does not differ significantly from the saturated model, the loss of the nonsignificant paths does not affect the fit of the model. Thus, the influence of these paths is negligible, and following the law of parsimony, they can be omitted without affecting the model. Also, the effect size for the model after dropping the nonsignificant paths increases from $22.7 \%$ to $25.3 \%$. Figure 1 depicts the final model (only significant paths are included). 


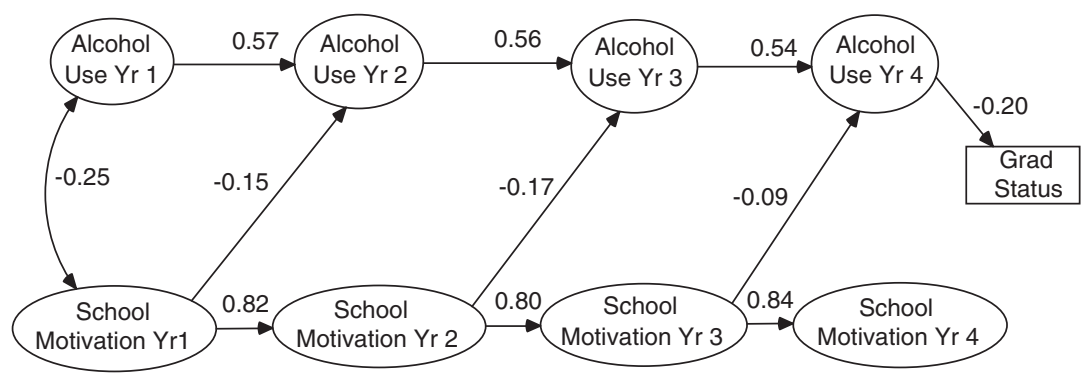

FIGURE 1 Latent factor structural model for alcohol use, school motivation, and graduation status. Numbers are standardized beta weights.

\section{Marijuana Use and School Motivation}

Alcohol use was replaced in the previous model by marijuana use. The final model indicated a correlation between marijuana use and school motivation at Wave 1 , small but significant effects of school motivation at Waves 1 and 2 on marijuana use at Waves 2 and $3\left(\beta_{\mathrm{s}}=-.10\right.$ and -.08 , respectively), and an effect of marijuana use at Wave 4 on graduation status ( $\beta=-.26$ ). The fit statistics comparing the saturated model and the final model with nonsignificant paths removed are reported in Table 3. The final model fit statistics were: $\chi^{2}(97)=205.849 ; \chi^{2} / d f=2.12$; $\mathrm{CFI}=.996$; RMSEA $=.041$. Again, although this $\chi^{2}$ does not differ significantly from the saturated model, the loss of the nonsignificant paths does not affect the fit of the model. Also, the effect size without the nonsignificant paths increased from $15.3 \%$ to $18.3 \%$. Figure 2 depicts the final model (only significant paths are included).

\section{Gender Differences in Alcohol and Marijuana Use Models}

The preceding model with alcohol use, school motivation, and graduation status was estimated in two-group design by gender. Tests of invariance on the measurement model showed differences in the binge variable loadings by gender, but no other variable loadings varied by gender. Males showed an effect of Wave 1 school motivation on Wave 2 alcohol use $(\beta=-.22)$. Wave 2 school motivation predicted Wave 3 alcohol use for males $(\beta=-.21)$ and for females $(\beta=-.10)$, and Wave 4 alcohol use predicted graduation status for males $(\beta=-.13)$ and for females ( $\beta=-.26)$. For females, Wave 3 alcohol use also predicted Wave 4 school motivation $(\beta=-.12)$. Although loadings and significance levels appeared to differ by gender, further analyses did not demonstrate this. The 
TABLE 3

Fit Statistics for the Models of Alcohol Use, Marijuana Use, and School Motivation

\begin{tabular}{lcccccc}
\hline Model & $d f$ & $\chi^{2 a}$ & $\chi 2$ Difference $^{b}$ & $\chi 2 / d f$ & CFI & RMSEA \\
\hline $\begin{array}{l}\text { Alcohol use as predictor } \\
\text { Saturated }\end{array}$ & 160 & 476.318 & - & 2.977 & .989 & .054 \\
$\begin{array}{l}\text { Final model (only significant paths) } \\
\text { Marijuana use as predictor }\end{array}$ & 164 & 477.499 & $1.181 \mathrm{~ns}$ & 2.912 & .989 & .053 \\
Saturated & & & & & & \\
Final model (only significant paths) & 97 & 201.150 & - & 2.186 & .996 & .042 \\
\hline
\end{tabular}

${ }^{\mathrm{a}}$ All $\chi^{2}$ values $p<.05 .{ }^{\mathrm{b}} \chi^{2}$ difference is change from the saturated model.

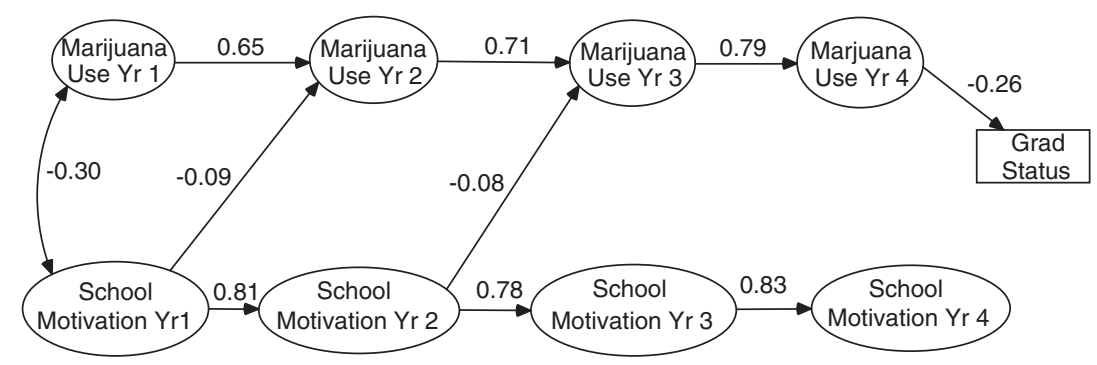

FIGURE 2 Latent factor structural model for marijuana use, school motivation, and graduation status. Numbers are standardized beta weights.

overall fit statistics were: $\chi^{2}(328)=739.207 ; \chi^{2} / d f=2.25 ; \mathrm{CFI}=.986$; RMSEA $=.043$.

The preceding model with marijuana use, school motivation, and graduation status was performed in two-group design by gender. Tests of invariance on the measurement model revealed no gender differences in factor loadings. Both males and females showed a small effect of school motivation at Wave 1 on Wave 2 marijuana use (males $\beta=-.09$, females $\beta=-.09$ ), and a stronger effect of Wave 4 marijuana use on graduation status (males $\beta=-.27$, females $\beta=-.24$ ). Although the males showed an effect of Wave 2 school motivation on Wave 3 marijuana use $(\beta=-.09)$, this path was not significantly different between genders. The overall fit statistics were: $\chi^{2}(194)=354.653 ; \chi^{2} / d f=1.83 ; \mathrm{CFI}=.994 ; \mathrm{RMSEA}=.035$.

\section{Differences in Alcohol and Marijuana Use Models by Wave 1 Use}

For the alcohol use, school motivation, and graduation status model, two groups were created-those who had any level of alcohol use by Wave 1 
$(n=423)$ and those who had never used at Wave $1(n=251)$. Before the model was estimated, $t$ tests were performed on the school motivation and alcohol use variables and on age to check for mean differences. Results showed that at almost all waves, all measures of alcohol use were greater and school bonding was lower for those who had initiated use by Wave 1 as opposed to those who had not (a table of these results is available on request). Age did not differ between Wave 1 users and nonusers. Tests of invariance on the measurement model showed that all the alcohol variable factor loadings differed by group, but the school motivation variable factor loadings did not. The SEM was then estimated with the Wave 1 alcohol use latent variable dropped from the model to control for covariance with group selection. The resulting model was estimated in a two-group analysis. Wave 1 alcohol users and nonusers showed some effect of Wave 1 school motivation on Wave 2 alcohol use (users $\beta=-.21$, nonusers $\beta=-.29$ ), Wave 2 school motivation on Wave 3 alcohol use (users $\beta=-.15$, nonusers $\beta=-.21$ ), and Wave 4 alcohol use on graduation status (users $\beta=-.17$, nonusers $\beta=-.15$ ). For those who had not used alcohol by Wave 1, school motivation at Wave 3 also predicted alcohol use at Wave $4(\beta=-.17)$, and school motivation at Wave 4 predicted graduation status $(\beta=.16)$. The two groups, however, only had significantly different paths for the prediction of alcohol use from Wave 3 to Wave 4 , whereas Wave 1 alcohol users had a significant beta ( $\beta=.56)$, but the path was not found $(\beta=.07)$ for those who did not use alcohol at Wave 1 . The overall fit statistics for this model were: $\chi^{2}(232)=637.018 ; \chi^{2} / d f=2.75 ; \mathrm{CFI}=.985 ; \mathrm{RMSEA}=.051$. Figure 3 shows the final model (only significant paths are included).

For the marijuana use, school motivation, and graduation status model, two groups were created-those who had any level of marijuana use by Wave $1(n=318)$ and those who had never used at Wave $1(n=349)$. Before the model was estimated, $t$ tests were performed on the school motivation and marijuana use variables and on age to check for mean differences. Results indicated that at almost all waves, both measures of marijuana use were greater in all waves, and school bonding and usefulness in the first two waves were lower for those who had initiated use by Wave 1, as opposed to those who had not (a table of these results is available on request). Wave 1 marijuana users were significantly older $(M=14.63$ years, $S D=.81)$ than nonusers $(M=14.50$ years, $S D=.85), t(665)=$ $-2.639, p<.01$, but this difference was minimal and therefore we did not control for age in our analyses. Tests of invariance on the measurement model again indicated that the marijuana variable factor loadings differed by group, but the school motivation variable factor loadings did not. The SEM was then estimated in a two-group analysis with the Wave 1 
(a) Wave 1 users

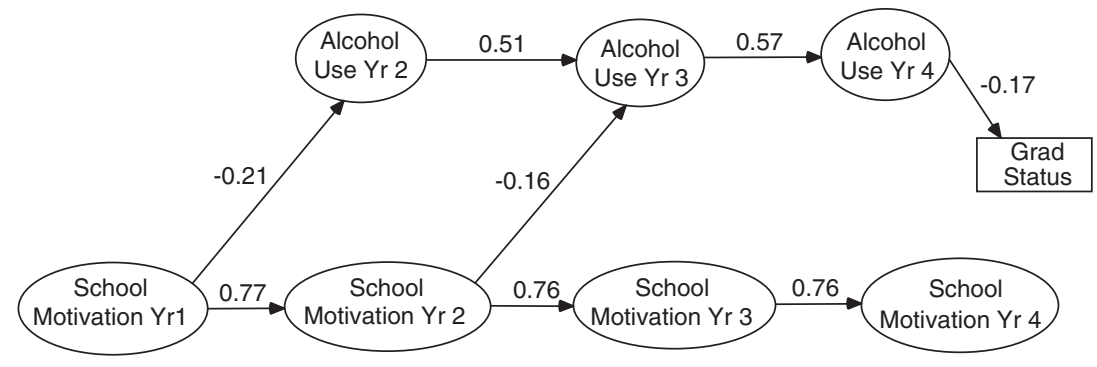

(b) Wave 1 nonusers

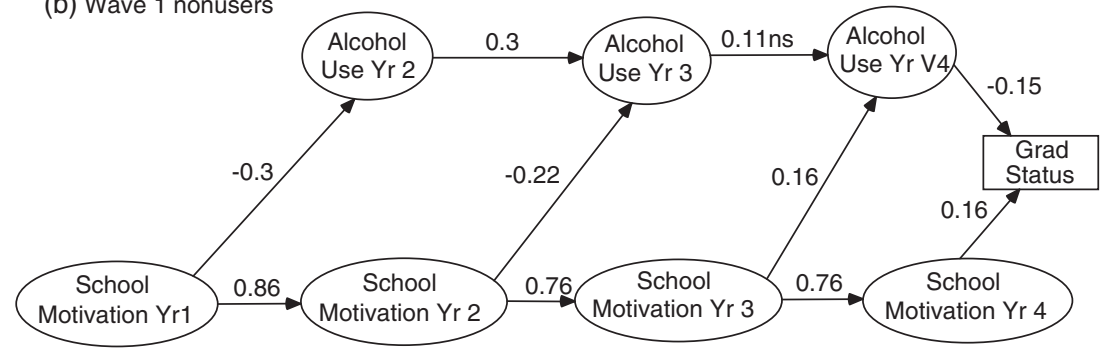

FIGURE 3 Latent factor structural models for alcohol use, school motivation, and graduation status by Wave 1 users (a) and Wave 1 nonusers (b) of alcohol. Numbers are standardized beta weights.

marijuana use latent variable dropped from the model to control for covariance with group selection. Both Wave 1 marijuana users and nonusers showed small effects of Wave 1 school motivation on Wave 2 marijuana use (users $\beta=-.21$, nonusers $\beta=-.14$ ), and an effect of Wave 4 marijuana use on graduation status (users $\beta=-.15$, nonusers $\beta=-.18$ ). The overall fit statistics for this model were: $\chi^{2}(150)=271.439 ; \chi^{2} /$ $d f=1.81 ; \mathrm{CFI}=.995 ; \mathrm{RMSEA}=.035$. Figure 4 shows the final model (only significant paths are included).

\section{DISCUSSION}

Our results are consistent with past research indicating a relationship between alcohol and marijuana use and lower educational motivation (Free, 1994; Paulson et al., 1990). Our longitudinal analyses, however, built on this past work by examining the cross-lagged effects of alcohol use or marijuana use and school motivation over all 4 high school years. It is also notable that we found these results within a sample of African American 
(a) Wave 1 users

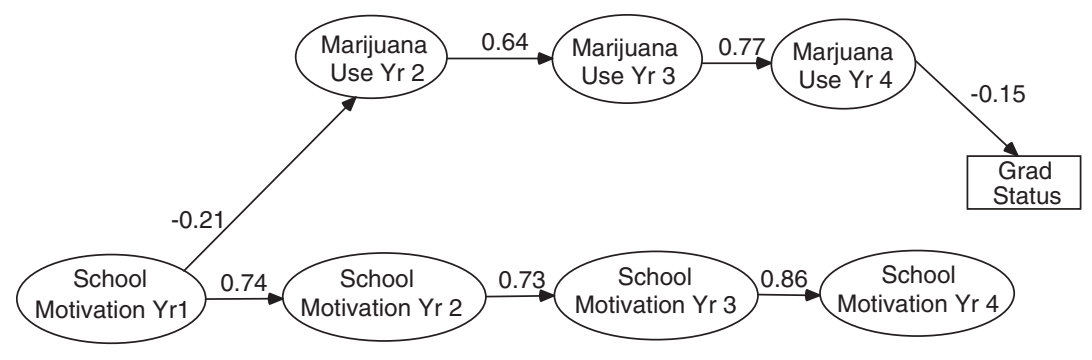

(b) Wave 1 nonusers

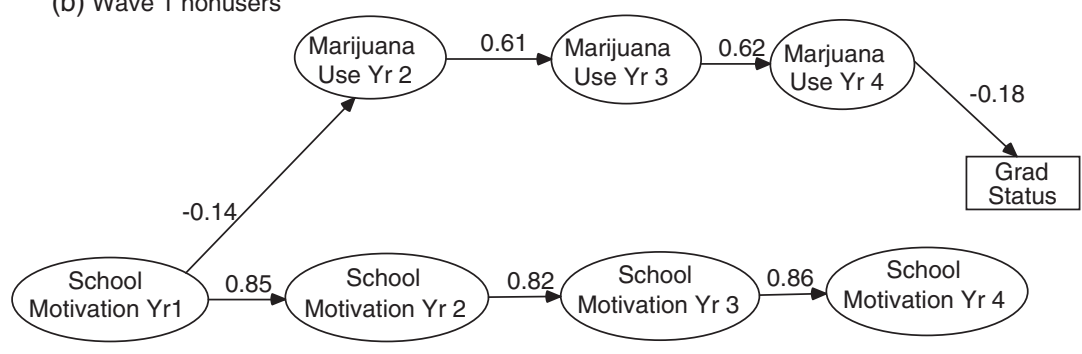

FIGURE 4 Latent factor structural models for marijuana use, school motivation, and graduation status by Wave 1 users (a) and Wave 1 nonusers (b) of marijuana. Numbers are standardized beta weights.

youth. In our overall model, we found that low school motivation contributes to continued drug use, but drug use does not appear to decrease subsequent school motivation. These results, though small in magnitude, support the school disengagement model of AOD use. We found only a slightly stronger association between school motivation and alcohol use than for marijuana use, as anticipated. School motivation appears to affect marijuana use early in high school, whereas effects of school motivation on alcohol use appear to be more persistent throughout the high school years. The lack of a large difference in strength of relations between alcohol and marijuana use as found by other researchers (Ellickson et al., 1998) may be due to differences in our samples. Ellickson et al. (1998) studied dropout 5 years after initial sampling in the seventh grade, whereas we examined alcohol and marijuana use throughout the high school years, and graduation status 18 months after expected graduation. Another explanation for our discrepant findings may be the difference in measures across studies. Previous studies examined individual indicators of constructs, whereas this study used a multivariate 
approach. Additionally, the small magnitude of the paths may have masked any substance-related differences.

We also found that use of alcohol and marijuana during high school increases the likelihood of not completing high school, even when given an additional 18 months after expected graduation. This corresponds to prior research indicating that AOD use during high school is associated with dropout (Eggert \& Herting, 1993; Ellickson et al., 1998; Friedman et al., 1985; Mensch \& Kandel, 1988; Newcomb \& Bentler, 1986; Schulenberg et al., 1994). The fact that our school motivation variable does not predict graduation status (except for Wave 1 alcohol nonusers) may be because of the strength of the drug use effect, or it may suggest that graduation is actually unconnected to school-related attitudes. These results support a problem-behavior theory interpretation that one type of problem behavior increases the likelihood of another problem behavior. Our results suggest that school disengagement predicts subsequent AOD use, but that as AOD use persists over time, youth may fall into a problem behavior syndrome and not graduate from high school.

We did not find any evidence to support the motivational deficit model. Use of alcohol or marijuana did not lead to a decrease in school motivation even after controlling for initiation before or after our first data-collection point. Although other researchers have found this relationship (Brook \& Newcomb, 1995; Ellickson et al., 1998; Friedman et al., 1985; Newcomb \& Bentler, 1986; Sanders et al., 2001; Wills et al., 1996), most of these studies were conducted with predominantly White samples. It is possible that substance use can lead to disengagement from school, but this may not be the primary direction of effects for African American youth.

Our results may be interpreted as reflecting an underlying disengagement from school among African American youth because of the effects of racial identity and discrimination. Fordham and Ogbu (1986) posit that African American youth may feel that academic achievement is a White domain because of past and current barriers to educational achievement and racial discrimination. According to this perspective, having a strong racial identity is related to a devaluing of academics. Steele and colleagues (Steele, 1997; Steele \& Aronson, 1995) suggest that African American youth may disengage from school because they feel their race is not highly valued by the larger society. Consequently, they disidentify with school to protect their self-concept because of the negative expectations they perceive in society. Processes such as these may be operative in our sample and may explain our findings connecting low school motivation and alcohol and marijuana use. Thus, if students are disengaged from academics, it may be because of the connections they make between 
racial discrimination and academic expectations and values. This, in turn, may increase the likelihood of substance use and other antisocial behaviors because school does not provide settings for prosocial behavioral development. Future research that examines the connections among racial identity, discrimination, school motivation, and alcohol and substance use longitudinally would help us explain the underlying cause of the associations we found.

This study sheds light on the timing of effects between AOD use and educational motivation, which may assist in the timing and construction of prevention programs for at-risk African American youth. Prevention of early AOD use may benefit by focusing on school engagement and making school more interesting and relevant for urban youth. Our results suggest that increasing educational motivation could slow AOD use rates, especially if implemented before initiation of use. Programs to create and maintain educational motivation begun before high school and continued through high school may help decrease AOD use and increase graduation rates in African American youth with low GPAs.

\section{Sex Differences, AOD Use, Educational Motivation, and Performance}

As observed recently (Bryant et al., 2000), but not in past research (Ellickson et al., 1998; Luthar \& D' Avanzo, 1999; Mensch \& Kandel, 1988; Stronski et al., 2000), we found few gender differences in our models. Both males and females show effects of school motivation on alcohol use, but these relationships appeared early in high school for males, whereas these relationships appeared later in high school for females. Luthar and D'Avanzo (1999) found a similar relationship for males, but not for females. This was a cross-sectional study of 10th-graders, however, so it is possible that age or cohort effects may have obscured effects for females. Additionally, the measurement model differed for males and females for binge drinking. This variable had mostly stronger loadings for females than males, which may have biased our results. For the marijuana use model, both males and females showed an early effect of school motivation on marijuana use and more marijuana use was predictive of not graduating from high school, but no sex differences were found in this model. Epidemiological data have shown a decrease in the past decade in the gender gap for marijuana use, with amount of use for both males and females being about the same for high school students in the 1990s $(7.7 \%$ in males vs. 6.6\% in females in 2000; Office of Applied Studies, 2002). Consequently, our model may be less able to detect sex differences in effects of motivation on marijuana use. It is also possible that in a single 
school district and among academically at-risk, African American students, sex plays a smaller role in the educational motivation-AOD use linkage than found in previous research.

\section{Effect of Time of Initiation}

Finally, following several researchers (Bray et al., 2000; Bryant et al., 2000; Ellickson et al., 2001), we examined differences in our models by comparing those who had not initiated alcohol or marijuana use by Wave 1 with those who had initiated use. Those who initiated alcohol use early tend to have different levels of alcohol use and variance in use, with higher means and greater variance for the early users. Both early and late initiators showed an effect of school motivation on alcohol use for the first two waves, but only Wave 1 nonusers continued to show this effect late in high school and demonstrated a positive effect of motivation on graduation status. Thus, for early alcohol nonusers, having higher school motivation may be protective against alcohol use throughout high school and may increase their chances of graduating high school. Early marijuana users and nonusers did not show differences in the model. Both groups had early school motivation predicting less marijuana use, and marijuana use decreased their chances of graduating high school. Thus, for early users of alcohol and marijuana, variance in school motivation generally does not affect later use, whereas a decrease in school motivation for early alcohol nonusers could be detrimental by promoting increased alcohol use and decreasing high school completion. These results vary from those of Bryant et al. (2000) in a national sample. Their longitudinal model of cigarette use, academic achievement, school bonding, and school misbehavior varied for lower school bonding relating to subsequent cigarette use for early cigarette users, but not in early nonusers. One reason for the difference in findings may the different substances studied or sample differences. The greater likelihood of cigarette use being tolerated, or at least more likely to be used on school grounds than alcohol or marijuana, may expose students to delinquent peers in the school environment. Thus, early users may have less school bonding early in high school, promoting subsequent cigarette use. Early alcohol and marijuana users, on the other hand, may be using for reasons unrelated to school. For these students, variation in educational motivation may not affect use patterns. Finally, because little research has focused on urban academically at-risk, African American youth, we cannot dismiss the possibility that differences in our findings from Bryant et al. are due to ethnic and demographic differences in our samples. 


\section{Study Limitations}

Some limitations of our study should be noted. Our sample only included youth who had eighth-grade GPAs of 3.0 or lower, and so may not generalize to the larger population of African American youth. Yet, we found the complete range of GPAs during the high school years including several A students (Zimmerman, Caldwell, \& Bernat, 2002), which may mitigate this limitation. Another limitation is that all the data are from selfreports. The tendency for respondents to report in socially desirable ways, for example, may reduce the variance available to explain in the dependent variables. This was addressed to some degree in two ways. First, the alcohol and marijuana use measures were collected by paperand-pencil questionnaire after the interview to minimize social influence in measuring these behaviors. Second, in our models, some of the method variance was accounted for in our analytical strategy by including correlations of error variances for variables over time. This enhances our confidence that the results cannot be explained away by similar method variance alone. The low correlation of the school usefulness items in our measure of school motivation could be a cause for concern. We kept this scale so our factor would more adequately indicate motivation. Also, although we measured expectation to go on to college in the study, the manner in which this question was asked was changed during the study. Thus, inclusion of these items would have been detrimental to the stability of our measurement model and problematic for the overall model. Additionally, although our factor may not include all possible items one could imagine for motivation, it does indicate prosocial connections to school and school work that imply motivation to staying in school. These motivation items may be especially important for an adolescent's decision to drop out of high school.

Another limitation with our study is that the effects we found were small. However, by controlling for the prior years of drug use and school motivation, very little variance is left to be explained. Our use of a 1-year latency instead of larger time gaps may have decreased our chances of significant findings. Thus, our analyses may actually be a conservative test of our hypotheses. The fact that we found any relationships suggests that alcohol and marijuana use and school motivation may actually be more strongly related than our results indicated. Also, using a 1-year latency is the typical approach because there is little theoretical rationale for longer latencies. It is also possible that the latency period differs as youths progress in high school. The results of the present study suggest that future research testing developmental differences of the latency period for the linkage between substance use and school motivation would be useful. 
The SES and ethnic characteristics of our sample are another limitation to generalization of our results. Although our study includes only African American youth, it may not be appropriate to include multiple ethnic groups in such a study because differences in the antecedents of dropout have been documented across ethnic groups. Ellickson et al. (1998), for example, found lower educational aspiration predicted dropout for African American youth, but repeating a grade and actual grades were more predictive of dropout for Whites. Our results are not consistent with this, as school motivation did not predict graduation status in our models; however, the Ellickson et al. study suggests the importance of a further analysis of African American adolescents. Additionally, the rates of alcohol use in our sample did not differ from national samples. For 30-day use, our sample in Wave 2 (10th grade) showed a $27.7 \%$ prevalence, whereas in the Monitoring the Future study, African American, 10th graders had a $27.9 \%$ to $36.2 \%$ prevalence depending on sampling area (Wallace et al., 1999). In the National Household Survey of Drug Abuse, 12- to 17-year-old African Americans had a $13.1 \%$ prevalence nationally and a 16\% prevalence in Michigan (Office of Applied Studies, 1999; Wright \& Davis, 2001). Our reported marijuana use prevalence (past year, $33.4 \%$ in Wave $1,41.1 \%$ in Wave 2) is higher than national samples. For the past year usage, in the Monitoring the Future study, African American 8th graders had an $8.3 \%$ to $10.6 \%$ prevalence and 10th graders had a $12.6 \%$ to $16.1 \%$ prevalence (Wallace et al., 1999), whereas in the National Household Survey, 12- to 17-year-old African Americans had a 12.1\% prevalence, and in Michigan the 30-day use prevalence was 7.8\% (Office of Applied Studies, 1999; Wright \& Davis, 2001). Higher than national rates of drug use have been shown among minority youth when they live in largely segregated, relatively high-crime and high-poverty areas (Oetting \& Beauvais, 1990). Our selection of low GPA students may have also biased our sample toward higher drug use rates. Our rates of alcohol use may not differ from national samples because alcohol use is more ubiquitous and socially acceptable nationwide. Our results may also have been biased by using only an urban sample. Luthar and D'Avanzo (1999) found substance use and absenteeism to be higher for their suburban sample than for innercity youth; however, they posited that the consequences for even a small amount of use may be greater for inner-city youth than for suburban youth. Thus, examining an urban population may be particularly crucial because of the potential for increased risk associated with drug use for urban youth. In addition, the mostly blue-collar nature of the sample may be a limitation because it does not include a more socioeconomically diverse group. Yet, by having SES somewhat constant in our sample, we were able to assess our hypotheses within a sample that may differ in 
critical ways from both higher and lower SES groups. Although the results may not generalize to all youth, they may inform our understanding of a vital subset of them.

Furthermore, this analysis did not examine other possible third variables that could have explained our results. The general deviance theory states that all deviant behaviors are related to underlying personality, temperament, or childhood experiences. Thus, a person who does not feel motivated to do well in school may be drawn to the use of alcohol and marijuana, with neither behavior causing the other. Our findings, however, suggest that low school motivation may be a factor in increased use of alcohol or marijuana, but they do not suggest the opposite relationship. Other possible third variables are peer influences and school culture or norms. This sample, however, used only four schools, and although several students changed schools and even left the school district, most of the sample remained within a small number of often similar schools. Too few students were in any particular school outside of our original four for adequate power to examine school effects. Our research has added a foundation of temporal relationships between substance use and school motivation so that future research can examine these issues in more detail.

\section{CONCLUSION}

In conclusion, our study built on previous research by examining alcohol and marijuana use and school motivation over consecutive years throughout high school. School motivation appears to decrease the risk for AOD use, and AOD use during high school may decrease the chances for obtaining a high school diploma in African American youth. These findings support a school disengagement model as suggested by Hawkins and Weis (1985). In our sample, when the students are not engaged by their school, particularly if the students have not initiated AOD use, they are likely to use alcohol or marijuana, possibly as an alternative method of stimulation and challenge. Some support is also found for the motivational deficit model in that AOD use undermines chances for high school completion as found by Newcomb and Bentler (1986) and others (Eggert \& Herting, 1993; Ellickson et al., 1998; Friedman et al., 1985). Because the alcohol and marijuana use in our sample is being driven by lack of school motivation, however, most of our evidence supports the school disengagement model. A replication of this study within other ethnic groups would provide a valuable basis for comparisons between ethnic groups. 
Further research examining other moderating and mediating factors would also be informative.

\section{ACKNOWLEDGMENTS}

This research was funded by the National Institute on Drug Abuse, grant DA07484. The views or policies expressed do not necessarily reflect the views or policies of the National Institute on Drug Abuse. We would like to thank the school officials, the Program for Urban and Regional Affairs at the University of Michigan, Flint, and the youth who participated in the research. We also appreciate the reviewers thoughtful comments on earlier drafts of the manuscript.

\section{REFERENCES}

Adams, C. A., \& Singh, K. (1998). Direct and indirect effects of school learning variables on the academic achievement of African American 10th graders. The Journal of Negro Education, 67(1), 48-66.

Bachman, J. G., O'Malley, P. M., \& Johnston, L. D. (1980). Correlates of drug use, Part I: Selected measures of background, recent experiences, and life-style orientations. Monitoring the Future, Occasional Paper 8, Ann Arbor, MI: Institute for Social Research.

Barnes, G. M., \& Welte, J. W. (1986). Patterns and predictors of alcohol use among 7-12th grade students in New York State. Journal of Studies on Alcohol, 47, 53-60.

Battin-Pearson, S., Newcomb, M. D., Abbott, R. D., Hill, K. G., Catalano, R. F., \& Hawkins, J. D. (2000). Predictors of early high school dropout: A test of five different theories. Journal of Educational Psychology, 92, 568-582.

Bray, J. W., Zarkin, G. A., Ringwalt, C., \& Qi, J. (2000). The relationship between marijuana initiation and dropping out of high school. Health Economics, 9, 9-18.

Brook, J. S., \& Newcomb, M. D. (1995). Childhood aggression and unconventionality: Impact on later academic achievement, drug use, and workforce involvement. Journal of Genetic Psychology, 156(4), 393-410.

Brown, T. N., Schulenberg, J., Bachman, J. G., O'Malley, P. M., \& Johnston, L. D. (2001). Are risk and protective factors for substance use consistent across historical time?: National data from the high school classes of 1976 through 1997. Prevention Science, 2(1), 29-43.

Bryant, A. L., Schulenberg, J., Bachman, J. G., O'Malley, P. M., \& Johnston, L. D. (2000). Understanding the links among school misbehavior, academic achievement, and cigarette use: A national panel study of adolescents. Prevention Science, 1(2), 71-87.

Coombs, R. H., Wellisch, D. K., \& Fawzy, F. I. (1985). Drinking patterns and problems among female children and adolescents: A comparison of abstainers, past users, and current users. American Journal of Drug and Alcohol Abuse, 11, 315-348.

Dewey, J. D. (1999). Reviewing the relationship between social factors and substance use for elementary, middle, and high school students. Journal of Primary Prevention, 19(3), 177-225.

Dornbusch, S. M., Erickson, K. G., Laird, J., \& Wong, C. A. (2001). The relation of family and school attachment to adolescent deviance in diverse groups and communities. Journal of Adolescent Research, 16(4), 396-422. 
Eggert, L. L., \& Herting, J. R. (1993). Drug involvement among potential dropouts and "typical" youth. Journal of Drug Education, 23(1), 31-55.

Ellickson, P., Bui, K., Bell, R., \& McGuigan, K. A. (1998). Does early drug use increase the risk of dropping out of high school? Journal of Drug Issues, 28(2), 357-380.

Ellickson, P. L., Tucker, J. S., Klein, D. J., \& McGuigan, K. A. (2001). Prospective risk factors for alcohol misuse in late adolescence. Journal of Studies on Alcohol, 62, 773-782.

Fordham, S., \& Ogbu, J. (1986). Black students' school success: Coping with the burden of acting white. Urban Review, 18, 176-206.

Free, M. D. Jr. (1994). Religiosity, religious conservatism, bonds to school, and juvenile delinquency among three categories of drug users. Deviant Behavior, 15, 151-170.

Friedman, A. S., Glickman, N., \& Utada, A. (1985). Does drug and alcohol use lead to failure to graduate from high school? Journal of Drug Education, 15(4), 353-364.

Hawkins, J. D., \& Weis, J. G. (1985). The social development model: An integrated approach to delinquency prevention. Journal of Primary Prevention, 6(2), 73-97.

Hirschi, T. (1998). Social bond theory. In F. T. Cullen, \& R. Agnew (Eds.) Criminological theory: Past to present (pp. 167-174). Los Angeles: Roxbury.

Johnston, L. D., \& O'Malley, P. M. (1986). Why do the nation's students use drugs and alcohol: Self-reported reasons from nine national surveys. Journal of Drug Issues, 16, 29-66.

Johnston, L. D., O'Malley, P. M., \& Bachman, J. G. (1988). Illicit drug use, smoking and drinking by America's high school students, college students, and young adults, 1975-1987. Rockville, MD: National Institute on Drug Abuse.

Kandel, D. B. (1980). Drug and drinking behavior among youth. Annual Review of Sociology, 6 , 235-285.

Luthar, S. S., \& D'Avanzo, K. D. (1999). Contextual factors in substance use: A study of suburban and inner-city adolescents. Development and Psychopathology, 11, 845-867.

Maton, K. I., \& Zimmerman, M. A. (1992). Psychosocial predictors of substance use among urban Black male adolescents. Drugs and Society, 6, 79-113.

MacCallum, R. C., Browne, M. W., \& Sugawara, H. M. (1996). Power analysis and determination of sample size for covariance modeling. Psychological Methods, 2, 130-149.

Mensch, B. S., \& Kandel, D. B. (1988). Dropping out of high school and drug involvement. Sociology of Education, 61, 95-113.

Murdock, T. B. (1999). The social context of risk: Status and motivational predictors of alienation in middle school. Journal of Educational Psychology, 91(1), 62-75.

Nakao, K., \& Treas, J. (1990a). Computing 1989 occupational prestige scores (GSS Methodological Report No. 70). Chicago: National Opinion Research Center.

Nakao, K., \& Treas, J. (1990b). The 1989 socioeconomic index of occupations: Construction from the 1989 occupational prestige scores (GSS Methodological Report, No 74). Chicago: National Opinion Research Center.

Newcomb, M. D., \& Bentler, P. M. (1986). Drug use, educational aspirations, and work force involvement: The transition from adolescence to young adulthood. American Journal of Community Psychology, 14(3), 303-321.

Oetting, E., \& Beauvais, F. (1990). Adolescent drug use: Findings of national and local surveys. Journal of Clinical and Consulting Psychology, 58, 385-394.

Office of Applied Studies. (1999). National Household Survey on Drug Abuse: Population estimates 1998. Rockville MD: Substance Abuse and Mental Health Services Administration.

Office of Applied Studies (2002). Summary of findings from the 2000 National Household Survey on Drug Abuse. Rockville, MD: Substance Abuse and Mental Health Services Administration. 
Paulson, M. J., Coombs, R. H., \& Richardson, M. A. (1990). School performance, academic aspirations, and drug use among children and adolescents. Journal of Drug Education, 20(4), 289-303.

Ramirez-Valles, J., Zimmerman, M. A., \& Newcomb, M. D. (1998). Sexual risk behavior among youth: Modeling the influence of prosocial activities and socioeconomic factors. Journal of Health and Social Behavior, 39, 237-253.

Sanders, C. E., Field, T. M., \& Diego, M. A. (2001). Adolescents' academic expectations and achievement. Adolescence, 36, 795-802.

Schulenberg, J., Bachman, J. G., O'Malley, P. M., \& Johnston, L. D. (1994). High school educational success and subsequent substance use: A panel analysis following adolescents into young adulthood. Journal of Health and Social Behavior, 35, 45-62.

Steele, C. (1997). A threat in the air: How stereotypes shape intellectual identity and performance. American Psychologist, 52, 613-629.

Steele, C. M., \& Aronson, J. (1995). Stereotype threat and the intellectual test performance of African Americans. Journal of Personality \& Social Psychology, 69, 797-811.

Stronski, S. M., Ireland, M., Michaud, P. A., Narring, F., \& Resnick, M. D. (2000). Protective correlates of stages in adolescent substance use: A Swiss national study. Journal of Adolescent Health, 26, 420-427.

Thorlindsson, T., \& Vilhjalmsson, R. (1991). Factors related to cigarette smoking and alcohol use among adolescents. Adolescence, 26(102), 399-418.

Wallace, J. M., Forman, T. A., Guthrie, B. J., Bachman, J. G., O’Malley, P. M., \& Johnston, L. D. (1999). The epidemiology of alcohol, tobacco and other drug use among black youth. Journal of Studies on Alcohol, 60(6), 800-809.

Watson, A. L. (1990). A descriptive analysis of parent and teacher perceptions regarding parent involvement in a program for the preschool handicapped. Dissertation Abstracts International, 51, 1501.

Wills, T. A., McNamara, G., Vaccaro, D., \& Hirky, A. E. (1996). Escalated substance use: A longitudinal grouping analysis from early to middle adolescence. Journal of Abnormal Psychology, 105(2), 166-180.

Wothke, W. (2000). Longitudinal and multi-group modeling with missing data. In T. D. Little, K. U. Schnabel, \& J. Baumert (Eds.) Modeling longitudinal and multiple group data: Practical issues, applied approaches and specific examples (pp. 219-240). Mahwah, NJ: Erlbaum.

Wright, D., \& Davis, T. R. (2001). Youth substance use: State estimates from the 1999 National Household Survey on Drug Abuse. Rockville, MD: Substance Abuse and Mental Health Services Administration.

Zimmerman, M. A., Caldwell, C. H., \& Bernat, D. H. (2002). Discrepancy between self-report and school record GPA: Correlates with psychosocial outcomes among African American adolescents. Journal of Applied Social Psychology, 32(1), 86-109. 